\title{
A possible Molecular Mechanism of Adenomyosis
}

\author{
Guoyun Wang* \\ Department of Obstetrics and Gynecology, Qilu Hospital of Shandong University, China
}

Submission: April 09, 2017 ; Published: May 02, 2017

*Corresponding author: Guoyun Wang, Department of Obstetrics and Gynecology, Qilu Hospital of Shandong University, Jinan 250012, China, Tel: +8618560081729; Email: wangguoy@sdu.edu.cn

\section{Mini Review}

Adenomyosis, an estrogen-dependent inflammatory disease, is defined as the presence of endometrial glands and stroma deep within the myometrium [1]. The main clinical features of adenomyosis are dysmenorrhea and menorrhagia, which are significantly associated with peritoneal endometriosis in infertile patients at reproductive age [2,3]. The only difference between adenomyosis and endometriosis is the site of endometriotic tissues, that is, inside or outside the uterus [4]. Thus, knowledge on the endometriotic cell origin is indispensable for the development of preventive and targeted treatment strategies for adenomyosis. The most widely accepted theory on the pathogenesis of adenomyosis is the down growth and invagination of the endometrium into the myometrium [5]. However, the possible mechanism of gland invagination from the endometrium deep into the underlying myometrium is unknown.

Epithelial mesenchymal transition (EMT) and its converse, mesenchymal epithelial transition (MET), are concepts defined decades ago [6]. Once epithelial cells become competent to respond to EMT-inducing signals, these signals can promote the disruption of the intercellular adhesion complexes and the loss of the apicobasal polarity of the epithelial cells, a prime feature crucial for cells to leave the epithelium and achieve migration potentiality [7]. Many studies indicated that EMT is a crucial process in adenomyosis and endometriosis lesions [8,9], and the endometrium and inner myometrium are closely apposed without any intervening basement membrane; thus, EMT events might occur here.

Macrophages have been known to play important roles in the adenomyosis process [4]. One study reported an increased stromal macrophage population in the functional layer of the endometrium in patients experiencing diffuse and focal adenomyosis [10]. Another study indicated that, after treating adenomyosis patients with the gonadotrophin releasing hormone (GnRH) agonist, the infiltration of CD68-positive macrophages is significantly decreased in the endometrium of adenomyotic women [11].
Abnormal levels of macrophages, which are important components of immune cells, have been largely reported in adenomyosis [12]. Increased knowledge on the immune aspects of the pathogenesis of adenomyosis is needed for this debilitating condition. To our knowledge, macrophages, which play important roles in innate and acquired immunity, together with natural killer cells and cytotoxic T-lymphocytes in healthy women, can destroy misplaced endometrial cells [13]. The EMT process induced by macrophages has been investigated systematically in tissue repair, remodeling, fibrosis [14], and tumor progression [15]. Alternatively activated (M2) macrophages are the major type associated with the tumor EMT process. Similar to tumor progression, adenomyosis also exhibits the EMT process.

Given that macrophages and EMT are all involved in the adenomyosis process, and the definite mechanism by which macrophages promote the development of adenomyosis is vague, we presumed that macrophages may induce endometrial epithelial cells to undergo EMT, because macrophages can induce EMT in many other diseases. Thus, EMT induced by macrophages might be an effective molecular mechanism to promote adenomyosis.

Adenomyosis, an estrogen-dependent inflammatory disease, is defined as the presence of endometrial glands and stroma deep within the myometrium [1]. The main clinical features of adenomyosis are dysmenorrhea and menorrhagia, which are significantly associated with peritoneal endometriosis in infertile patients at reproductive age [2,3]. The only difference between adenomyosis and endometriosis is the site of endometriotic tissues, that is, inside or outside the uterus [4]. Thus, knowledge on the endometriotic cell origin is indispensable for the development of preventive and targeted treatment strategies for adenomyosis. The most widely accepted theory on the pathogenesis of adenomyosis is the down growth and invagination of the endometrium into the myometrium [5]. However, the possible mechanism of gland invagination from the endometrium deep into the underlying myometrium is unknown. 
Epithelial mesenchymal transition (EMT) and its converse, mesenchymal epithelial transition (MET), are concepts defined decades ago [6]. Once epithelial cells become competent to respond to EMT-inducing signals, these signals can promote the disruption of the intercellular adhesion complexes and the loss of the apicobasal polarity of the epithelial cells, a prime feature crucial for cells to leave the epithelium and achieve migration potentiality [7]. Many studies indicated that EMT is a crucial process in adenomyosis and endometriosis lesions [8,9], and the endometrium and inner myometrium are closely apposed without any intervening basement membrane; thus, EMT events might occur here.

Macrophages have been known to play important roles in the adenomyosis process [4]. One study reported an increased stromal macrophage population in the functional layer of the endometrium in patients experiencing diffuse and focal adenomyosis [10]. Another study indicated that, after treating adenomyosis patients with the gonadotrophin releasing hormone (GnRH) agonist, the infiltration of CD68-positive macrophages is significantly decreased in the endometrium of adenomyotic women [11].

Abnormal levels of macrophages, which are important components of immune cells, have been largely reported in adenomyosis [12]. Increased knowledge on the immune aspects of the pathogenesis of adenomyosis is needed for this debilitating condition. To our knowledge, macrophages, which play important roles in innate and acquired immunity, together with natural killer cells and cytotoxic T-lymphocytes in healthy women, can destroy misplaced endometrial cells [13]. The EMT process induced by macrophages has been investigated systematically in tissue repair, remodeling, fibrosis [14], and tumor progression [15]. Alternatively activated (M2) macrophages are the major type associated with the tumor EMT process. Similar to tumor progression, adenomyosis also exhibits the EMT process.

Given that macrophages and EMT are all involved in the adenomyosis process, and the definite mechanism by which macrophages promote the development of adenomyosis is vague, we presumed that macrophages may induce endometrial epithelial cells to undergo EMT, because macrophages can induce EMT in many other diseases. Thus, EMT induced by macrophages might be an effective molecular mechanism to promote adenomyosis.

\section{References}

1. Ferenczy A (1998) Pathophysiology of adenomyosis. Human Reproduction Update 4(4): 312-322.

2. Khan KN, Kitajima M, Hiraki K, Fujishita A, Sekine I, et al. (2010) Changes in tissue inflammation, angiogenesis and apoptosis in endometriosis, adenomyosis and uterine myoma after $\mathrm{GnRH}$ agonist therapy. Hum Reprod 25(3): 642-653.

3. Kunz G, Beil D, Huppert P, Leyendecker G (2000) Structural abnormalities of the uterine wall in women with endometriosis and infertility visualized by vaginal sonography and magnetic resonance imaging. Hum Reprod 15(1): 76-82.

4. Ota H, Igarashi S, Hatazawa J, Tanaka T (1998) Is adenomyosis an immune disease? Human Reproduction Update 4(4): 360-367.

5. Bergeron C, Amant F, Ferenczy A (2006) Pathology and physiopathology of adenomyosis. Best Pract Res Clin Obstet Gynaecol 20(4): 511-521.

6. Alcorn D, Maric C, McCausland J (1999) Development of the renal interstitium. Pediatr Nephrol 13(4): 347-354.

7. Khan KN, Kitajima M, Hiraki K, Fujishita A, Nakashima M, Masuzaki $\mathrm{H}$ (2015) Involvement of Hepatocyte Growth Factor-Induced Epithelial-Mesenchymal Transition in Human Adenomyosis. Biology of Reproduction 92(2): 35.

8. Kunz G, Beil D, Huppert P, Noe M, Kissler S, et al. (2005) Adenomyosis in endometriosis--prevalence and impact on fertility. Evidence from magnetic resonance imaging. Hum Reprod 20(8): 2309-2316.

9. Chen YJ, Li HY, Huang CH, Twu NF, Yen MS, et al. (2010) Oestrogeninduced epithelial-mesenchymal transition of endometrial epithelial cells contributes to the development of adenomyosis. J Pathol 222(3): 261-270.

10. Matsuzaki S, Darcha C (2012) Epithelial to mesenchymal transitionlike and mesenchymal to epithelial transition-like processes might be involved in the pathogenesis of pelvic endometriosis. Human Reproduction 27(3): 712-721.

11. Tremellen KP, Russell P (2012) The distribution of immune cells and macrophages in the endometrium of women with recurrent reproductive failure. II: adenomyosis and macrophages. Journal of Reproductive Immunology 93(1): 58-63.

12. Khan KN, Kitajima M, Hiraki K, Fujishita A, Sekine I, et al. (2010) Changes in tissue inflammation, angiogenesis and apoptosis in endometriosis, adenomyosis and uterine myoma after GnRH agonist therapy. Hum Reprod 25(3): 642-653.

13. Dmowski WP, Gebel H, Braun DP (1998) Decreased apoptosis and sensitivity to macrophage mediated cytolysis of endometrial cells in endometriosis. Hum Reprod Update 4(5): 696-701.

14. Scotton CJ, Chambers RC (2007) Molecular targets in pulmonary fibrosis: the myofibroblast in focus. Chest 132(4): 1311-1321.

15. Galdiero MR, Garlanda C, Jaillon S, Marone G, Mantovani A (2013) Tumor associated macrophages and neutrophils in tumor progression. Journal of Cellular Physiology 228(7): 1404-1412. 
This work is licensed under Creative Commons Attribution 4.0 Licens DOI: 10.19080/JGWH.2017.04.555637
Your next submission with Juniper Publishers will reach you the below assets

- Quality Editorial service

- Swift Peer Review

- Reprints availability

- E-prints Service

- Manuscript Podcast for convenient understanding

- Global attainment for your research

- Manuscript accessibility in different formats (Pdf, E-pub, Full Text, Audio)

- Unceasing customer service

Track the below URL for one-step submission https://juniperpublishers.com/online-submission.php 